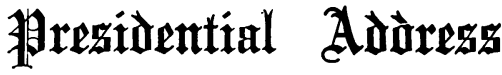

$$
\text { ON THE }
$$

\section{PRESENT POSITION OF THE NEURONE DOCTRINE IN RELATION TO NEURO-PATHOLOGY.}

Delivered before the Section of Pathology of the Royal Society of Mrdicine.

By F. W. MOTT, M.D., F R.C.P., F.R.S., PATHOLOGIST, LONDON COUNTY COUNCIL ASYLUMS; PHYSICIAN TO CHARING CROSS HOSPITAL.

[With Special Plates.]

Genthemen,-Allow me first to thank you for the great honour in electing me to the chair of this Section.

I was recently informed by the Senior Secretary that I should be expected to open this session by an address, and I propose therefore to give a general survey of the present position of the neurone concept, a subject in which I have been especially interested, as it is fundamental in neuro-pathology.

During the last fifteen years it has given rise to much discussion, to many experiments and observations, and to new modes of improving our knowledge of the minute structure and development of the nervous system.

The neurone theory was at first accepted by most neurologists without hesitation, as it explained so many facts in pathology;

when regeneration occurred it was owing to new fibres being formed by the cells of the sheath of Schwann. The question has long been in dispute whether regeneration takes place by a new outgrowth from the cell of origin or whether it is effected by the sheath ceils. Likewise, there have been two opposing theories with regard to the genesis of the nerve fibres, one being that the fibre is an outgrowth from the cell, the other that it is a product of the sheath cells. Consequently, the subject that I shall discuss first will be the genesis of the nerve fibre.

How is the nerve fibre formed? The answer given, first by Schwann and later by Kupfer, Balfour, Dohrn, and many others, and still more recently by Apathy, Bethe, and Schultze, is that the nerve fibre is the product of a chain of cells, which extends from the nerve cells to the peripheral termination; they assert that these sheath cellis secrete the fibrillae within their protoplasm. Certainly such an interpretation of the histological appearances could not be refuted till new methods of staining and new methods of experimentation were adopted to disprove this statement.

His, by his embryological researches, on the other hand, claimed that the axis cylinder and the other processess of the nerve cell were the outgrowths of the cell protoplasm. Then came the chrome silver method of Golgi, which, in the hands of Ramon y Cajal, Kölliker, Retzius, Len. hossek, Van Gehuchten, and many others, apparently demonstrated the fact that the whole nervous system consisted essentially of independent anatomical units; and the cylinder axon was an outgrowth of the nerve cell.

Ramon y Cajal was able to follow the development of the neurone from the neuroblast in al its stages, from the

but grave doubts were cast upon it, owing to observations and experi. ments made by those who dis. believed the inter. pretation put upon histological details by those who upheld the doctrine.

This controversy between scientific men seeking after truth was not without great advan. tages, for it led to the discovery of new methods of technique and new methods of embryological re. search, which now have finally esta blished on a firm basis the neurone concept, which I may remind you

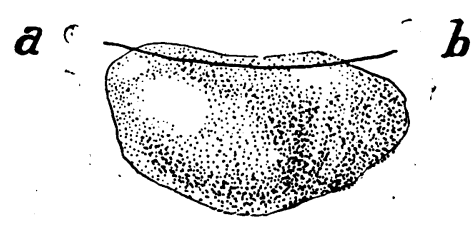

A.

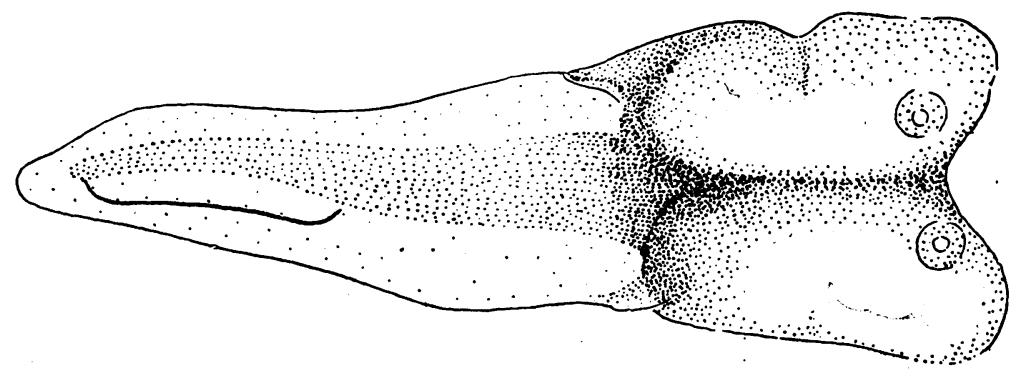

C. Fig. 1.-A, Frog embryo $2.7 \mathrm{~mm}$. long. The line $a-b$ indicates the incision for the removal
of the ganglion crest. B, C, Two double embryos, from each of which the ganglion crest has

B.

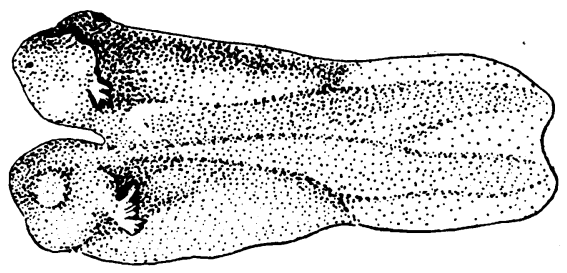
although reintroduced in the following terms by Waldeyer A neurone is a nerve cell and all its processes, including the protoplasmic processes or dendrons and the single axis cylinder process with its cone of origin, its collaterals or sidebranches, and its terminal arborization. The neurone theory is that the nervous system consists of innumerable such anatomically independent nervous units in con tiguity but not in continuity. There is interlacing of the processes but no network. The nervous units are genetically and trophically independent cellular organisms arranged in functionally correlated systems, communities, and constellations.

It is admitted by all that the nervous system consists of nerve fibres and nerve cells supported by neuroglia, and the main point of discussion has been the origin of the nerve fibres. Waller ${ }^{1}$ more than fifty years ago showed experimentally that a nerve separated from its ganglion underwent degeneration, and every one has admitted there must be some intimate relation between the ganglion cells and the nerves. But it was asserted that 4 first appearance of the short nervous. process up to the long outgrowth which formed the nerve fibre. His researches ex tended, over the most varied motor and sensory re. gions of the cen. tral as well as of the sympathetic nervous system. and fully confirmed the re. searches of His. These results of the researches of Cajal were soon followed by impor. tant researches of Ffeld, who was able to demonstrate that the nerve fibre is an outgrowth of the nerve cell. Moreover, he accurately followed the origin and further development , the neuro-fibrils. They are situated, as already His, Besta, and Lenhossek had observed, in the interior of the neuroblastic protoplasm, first in the form of a loose skein, and then they grow out from the nerve cell body into the nerve process. Held, however, like Hensen, finds that the nerve processes are not free, but grow into preformed tracts, which Hensen calls intracellular bridges; and he further believes that instances may arise where the neuro-fibrils of one cell grow into another cell, and commingling with the fibres of that cell pass out of its axon process. As Verworn remarks, these facts are interesting histological details, but are completely indifferent for the neurone doctrine.

If we look at the figures [Plate $I-1,2,3,4]$ given by the neuronists and the antineuronists, we can understand why this different interpretation of the mode of development of fibres should occur. Ross Harrison truly remarks it is impossible to decide by microscopic examination of sections of embryos whether the spindle-shaped cells lying around the nerve fibres form the fibres, or whether they simply [2550] 
ensheath processes of the nerve cells. . He states that his own observations upon the normal development of the salmon and frog had led him to a decided opinion in favour of the neurune conception, but the attitude of the opponents of the doctrine was such that the study of normal development.would never prove convincing; con. sequently he set about finding some means of differential experiment.

Profiting by the knowledge of the transplantation experiments in tadpoles of Born, Ross Harrison planned a new and exact method of study-namely, the removal in turn of each of the two structures in the developing embryo-frogs. Embryological studies had already shown that the source of the sheath cells was the ganglion crest; accordingly he removed this structure in the embryo Rana esculenta before any differentiation of nerve cells and fibres had occurred. The dorsal portion of the medullary tube and

the ganglion crest was removed, and the embryo was thus left with its nervous system as an open groove in its back, the walls of which contained the cells which would subsequently develop into the spinal motor cells. Two embryos so operated upon were joined back to back, so. as to prevent regeneration processes vitiating the result. (Fig., 1.) These ani. mals were allowed to live a certain time and grow; they were then killed and ex. amined carefully after. wards. by serial sec. tions. No spinal ganglia or sensory nerves were found, and what was of great interest was the fact that the motor nerves were found as fine proto. plasmic threads ex. tonding , from the spinal cord with not a single sheath cell around them (Fig. 2,C). The nerve consisted simply of delicate fibrils. This experi. ment shows that the ganglion crest forms the posterior spinal ganglion sensory nerves and the sheath cells. The conclusion is that the ganglion cells can form the nerve fibres without the aid of the sheath cells.

The next question Harrison sought to answer-and it is complementary to the last-was this: Can sheath cells without ganglion cells form the nerve fibres? He made the same incision as before, but instead of removing the ganglion crest he lifted it up and replaced it after removing with a fine pointed glass pipette the remainder of the medullary tube. The embryo developed normally, but remained almost motionless; subsequent examination showed that the sensory fibres and the sheath cells de veloped, but no motor fibres; although normally the motor and sensory fibres run together, and this would allow the fibres to the muscles ample opportunities of developing from the sheath cells if they were really the source of the motor fibres. (Fig. 2, D.)

He found, moreover, that nerves separated from their cells of origin degenerate rapidly, and no signs of regeneration were observed.

The question may be asked, Does the ganglion cell process extend as a nerve fibre to its peripheral termination? or is this process, as Hensen maintains, a differentiation of protoplasmic connexions already in situ? This view of Hensen, according to which protoplasmic bridges are supposed to be left between the dividing embryonic cells, has been supported by the difficulty of conceiving how it is possible for a nerve fibre to grow out a long distance (and always to arrive at the right place) in the case of regeneration of the nerves of the foot, after division of the sciatic nerve for example. Harrison sought to solve the problem thus: He cut out the medullary groove that will form the spinal cord of an embryo before there was any trace of cell differentiation, and placed a small piece of it in lymph removed from the lymph sac of a frog; the preparation was put on a cover.glass, and mounted on a hollow slide and sealed with paraffin. The lymph clots almost immediately and holds the trans. planted tissue in place.

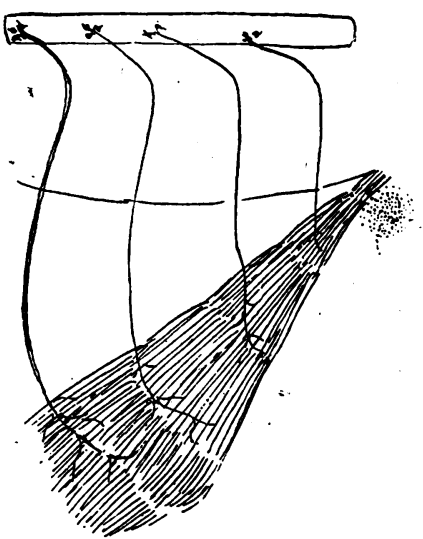

c.

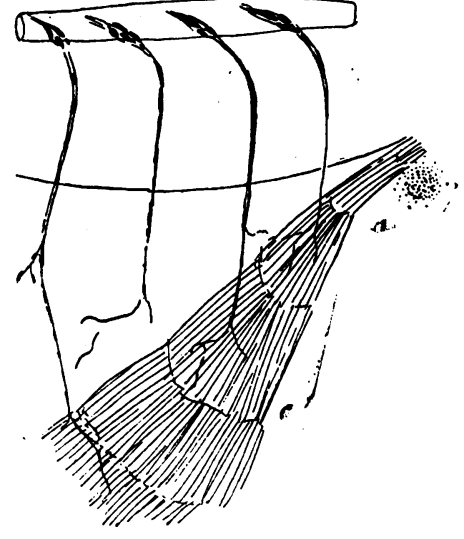

D. He has kept prepara. tions alive five weeks and watched the development of the neuroblast, and he has seen the axon develop and grow [see Plate II $-3,4,6]$. A some what similar structure to the cone of increase described by Cajal by his silver method of staining embryonic spinal cords [see Plate II-6] can bo seen. Probably it is also simular to the terminal balb of re generating axons found in the peripheral stump of a divided nerve. Harrison has observed a growth of $20 \mu$ in twenty-five minutes as shown in the figures. Control experiments with other tissues of the embryo gave no such results. These remarkable observations of Ross Harrison show beyond question that the nerve fibre begins as an outflow of hyaline protoplasm from cells situated within the central nervous system. This protoplasm is actively amoeboid; retaining its pseudopodia at its distal end, the protoplasm is drawn out into a thread which becomes the axis cylinder of a nerve fibre. Although Harrison has disproved the theory that the sheath cells form the essential portion of the nerve-namely, the axis cylinder-yet he fully admits, as all those. who uphold the neurone doctrine do, that the cells of the shesth of Schwann play an important rôle in the nutrition and production of the nerve fibre. These experiments of Harrison place the outgrowth theory of His on the safest of all foundations-namely, that of direct observation. It is, moreover, interesting and important to note briefly that Marinesco, Goldstein, Minea, and Nageotte have observed in transplanted spinal and sympathetic ganglia of warm. blooded and cold-blooded animals an outgrowth of fibrils from the ganglion cells. As Verworn truly says, the embryological basis of the neurone doctrine has been established beyond dispute. The formation of connexions of one neurone with another by fibrils, the parsage of fibrils from one nerve cell through another nerve cell are matters of detail which in no way. shake the fundamental principle 
of the neur sne concept-namely, the cell and its processes form a nerve unit which has a genetic independence. According to Kölliker, all the nerve fibres arise from nerve cells of the central nervous system and the ganglia. The peripheral nerve fibres are surrounded by special cells, constituting in the adult the sheath of Schwann. The latter appear when the axis cylinder is developed, and constitute for it a superficial envelope. These sheath cells all arise from the mesoderm and multiply by karyokinesis. According to Froriep, however, the cells of the sheath of Schwann of the peripheral nerves are probably, like the neuroglia cells, of ectodermal origin. Certainly Harrison's experiments seem to support Froriep's views.

The anatomical observations of Cajal and others I have named regarding the genetic independence of the neurone have thus been fully confirmed by the researches of Harrison. The next question is, Are the sheath cells of no further use than to enclose the axial core; in fact, is there a complete trophic independence of the nerve cell and its processes? Experimental and clinico-anatomical observations indicate that the sheath cells play an important part in regeneration after injury of the axon. To prove this statement we have only to consider the difference in the results on the extra-medullary and intra-medullary course of the axons of the posterior spinal ganglia after section of the posterior roots. Sherrington and many other observers have described fine medullated regenerated fibres around the cord-that is, central to the seat of injury-but only isolated observations have shown a few regenerated fibres in the exogenous systems of the posterior columns.* We may correlate these facts with the presence of sheath cells in the extra-medullary posterior roots and the absence of the same in their intra-medullary course. It was shown by Gudden that evulsion of the cranial nerve caused atrophy and disappearance of the nuclear cells of origin, and this method in his hands and that of his pupils, von Monakow and Forel, laid the foundation of much of our knowledge of the nuclear origin of the cranial nerves. Simple section of the nerves, as Nissl, Marinesco, Van Gehuchten, and others, have shown, produces chromolytic changes, but as a general rule the cells do not undergo atrophy. It may be assumed that evulsion was a more serious injury and destroyed not only all the sheath cells of the neuraxon up to the point of origin of the nerve from the central nervous system, but was also a much more serious injury of the neuraxon itself.

Before proceeding to describe the recent advances in our knowledge concerning the changes which take place in the central and peripheral ends of a divided nerve it will be well first to consider the changes in the nerve cells of origin as revealed by the Nissl method.

\section{Changes in the Cells due to Lesions of Cranial and} Peripheral Nerves.

Nissl first pablished (1892-1894) detailed accounts of the changes in the nerve cell (observed by his method of staining) produced by section of the nerves. Twenty-four hours after section of the facial nerve in the rabbit there is a reaction in the cells of the facial nucleus. The chromatic substances commence to disappear in limited regions of the cell body, and after two days instead of presenting the blocks of stainable substance, now known as the Nissl granules, there was observed a fine dust of coloured particles. By the third day the process had extended to the dendrons. At the end of five or six days the cell has changed its form, it has become rounder, the prolongations less visible and the protoplasm looks as if sprinkled with dust like particles of stainable substance. Daring this time the nucleus has changed its position and become eccentric. Nissl also studied the alterations in the cells of the posterior spinal ganglia produced by section. Marinesco repeated and confirmed Nissl's experiments, using the hypoglossal nerve. He was followed by Ballet et Dutil, Lugaro, Van Gehuchten, Flemming, and many others. The changes observed may be thus summarized: Swelling of the cell body with slight increase of volume of the nucleus and of the nucleolus, the cell becomes rounder and the prolongations in their turn swell; there is disintegration of the Nissl granules, a process which begins

*Again, although Marinesco, Minea, and Fickler have seen attempts at formation of regenerating fibres after transverse lesions of the spinal cord, there is no restoration of function, because there is no re-establishment of connexion with the appropriate neurones. in the central region of the cell near the axon-cone of origin. The first changes are observed twenty-four hours after section, and they progress until the whole perinuclear region exhibits this chromatolysis and the Nissl granules on the protoplasmic processes disappear. The nucleus becomes eccentric in proportion to the amount of chromatolysis. These changes are due to alterations of the osmotic conditions of the cell caused by the injury to its axon process, whereby fluid is absorbed from the ambient medium. Marinesco names this characteristic change "perinuclear chromatolysis"; a similar appearance of the nerve cells is seen in neuritis. I have observed it in all cases of alcoholic polyneuritis and in lead neuritis. This reaction of injury to the nerve cell when its axis cylinder process is injured is in direct confirmation of the correctness of the neurone doctrine, for if the sheath cells formed the axon it is much less likely that the nerve cell would show such changes, which may even proceed to their atrophy and disappearance. It is remarkable that when a nerve is divided only some motor spinal ganglion cells are so severely damaged that they do not recover but undergo atrophy and disappear, so it is found in polyneuritis some cells hardly show any change, while others are so injured as to be incapable of recovery and eventually atrophy and disappear. [Vide Plate I-6.] Again, in transverse lesions of the spinal cord, as shown by Pusateri, Marinesco, and Gordon Holmes, the Betz cells of the cortex undergo similar chromolytic changes which may proceed to atrophy, but the cells are affected very unequally, for we may observe two Betz cells lying side by side, the one seriously damaged and the other hardly affected at all. Drs. Sewell and Turnbull have investigated a case of transverse lesion of the spinal cord due to fracture of the spine at the level of the fifth cervica]. The boy died at Charing Cross Hospital eight weeks after the injury. The Betz cells at the top of the ascending frontal convolution showed all degrees of chromatolysis, from cells with hardly perceptible changes to complete disappearance of the Nissl granules. I have observed also in experimental poisoning by botulin, absinthe, phosphorus, and other poisons, also in acute and chronic poisoning of human beings, that the neurones are not equally affected. Still more striking is the fact that, after experimental ligature of all four arteries, 2 carotids and 2 vertebrals, or 2 carotids 1 vertebral, and 1 subclavian, whereby an experimental cortical anaemia in lower animals-for example, monkey, cat, and dog-was produced, the cells of the same type, for example, the Betz cells, were not equally affected; relatively only a few were so damaged as to undergo destruction. The conclusion is that the specific vital energy of some cells is greater than that of others, just the same as the individuals of a society are not all possessed of the same vital resistance to injury or poison; but as we know that the vital resistance of the individuals of a society is largely a matter of nutrition, fatigue, and powers of conservation of energy, so probably it is with the neurones. Those in which nutritional equilibrium is, either from inherent defect, fatigue, or other causes, in a low state, will suffer most.

I have also observed this chromatolysis of the Betz cells very marked in cases of chronic alcoholic and chronic lead polyneuritis ; it was more marked to my mind than could be accounted for by the small amount of degeneration of the pyramidal tracts, and I cannot help thinking that it was the effect of the poison on the whole system of efferent neurones concerned with reflex and voluntary movements plus the parenchymatous and peripheral inter. stitial polyneuritis [Plate I-6]. All the nearones, however, do not undergo destructive atrophy; probably only those in which the nucleus is extruded are incapable of recovery. My experience has taught me that even in severe cases of polyneuritis recovery may result from continued passive movements of all the joints and massage of the muscles. The ayoidance of pressure and weight of the bed-clothes in rendering $a$-footdrop permanent, the instruction of the patient to make voluntary effort by aid of attention and vision, and try to assist the operator making the passive movements ; the placing the feet against a board while lying in bed, and the daily placing the feet on the ground in the effort to feel the weight of the body supported by the limbs, all tond, by favouring incoming and outgoing stimuli, to open up the old paths or to restore function by new paths. This 
is no mere hypothesis, for it is based upon the fact that Munk found that monkeys in which the motor area had been removed much more completely regained movements when placed in a cage large enough to enable them to spring about and take free exercise.

Upon this assumption, therefore, that stimulus exercised an important influence upon regeneration of nerves, Halliburton and I carried out $\mathrm{a}$ series of investigations to see if regeneration of the motor nerves was interfered with iby cutting off, so far as we were able, stimuli from the spinal motor neurones of a limb. The following procedure was adopted: Unilateral section of the posterior roots from the third cervical to the third dorsal inclusive was performed, the animals used being monkeys. There was as a result a marked hypotonus of the limb, which hung useless as a flail, and the animal did not use it for refined voluntary purposive movements. Either the median or the ulnar nerves on the two sides were then divided and sutured. There was apparently no difference in the time taken for regeneration on the two sides, nor could I discover any more marked changes in the anterior horn cells of one side than of the other. Again, the motor' area of the right side of the brain was removed in an animal in which those same posterior roots had been divided; the nerves were divided on both sides, and the result was the same as in the previous related experiment. A third experiment wes performed : a unilateral section of the lumbo-sacral roots was combined with hemisection of the spinal cord in the mid. dorsal region and both sciatics were subsequently divided and sutured. Even in this experiment we could not claim that all sources of stimulus to the spinal motor neurones of the side of the double : lesion had been removed. Still, the greater part of the paths exercising any influence upon the discharge from the spinal motor neu. rones had been removed, and if stimulus really did play an important part in the nutritional activity necessary for regeneration of the motor nerves, after section of the axons of the motor neurones, it might be certainly ex pected that regeneration would be delayed on that side; but it was not, and this accords with the fact that the characteristic changes in the ganglion cells were not more apparent on the side of the double lesion than on the opposite side. A careful examination of sections of the spinal cord failed to show more ganglion cells presenting chromolytic changes on one side than the other. In order to avoid any personal bias, I tried to see if I could ascertain on which side the double lesion had been made by an examination of the anterior horns; but I failed entirely, although when I shifted the specimen to the posterior cornua it was quite evident from the atrophy of the fibres and changes in the cells. Plate I, 6, shows two degenerated cells on the side opposite to the spinal and root lesions.

The trophic activity of the spinal motor neurones is therefore in all probability independent of stimulus arriving from other neurones, They possess, indeed,

a trophic autonomy. The observations of Harrison sup. port this idea; moreover, this accords with the neurone doctrine of genetic and trophic independence. Direct injury of any part of the neurone will cause changes but not injury of neurones with which it is functionally bat not nutritionally correlated.

The axon consists of a number of conductile fibrils, and the more of these fibrils which are severed the greater will be the injury to the neurone. It is possible that fibrils constituting an axon may not come entirely from one cell in every case; there may be, as Held suggests, in some instances a commingling of fibrils proceeding from different cells to form the axon of a nerve in such a case it is conceivable that the reaction of injury would be less than when all the fibrils of a cell are divided.

We have briefly discussed what hap. pens to the cell when that portion of the neurone which is termed the axon is injured; I will now consider the changes which occur $(a)$ in the peripheral portion of the nerve, and $(b)$ in the central end of a divided nerve, in the light of modern researches, especially as revealed by the new silver method of Cajal, which shows that a neurone consists of fibrils which pass from the dendrons through the body of the cell to the axon, and con-

Fig. 3.-Wallerian degeneration of regenercat. Marchi method of taining. $(600$ dia. be [vide Plate II-5] sequently may blement of the neurone.

the conductile element of the neurone.

The appearances presented by fibres undergoing de generation when stained by the Marchi method are well known. I may call your attention to Fig. 3, which is of considerable interest for another reason to which I will briefly refer. The follow. ing experiment was performed by Halliburton and myself.

A small piece was resected from a nervein which regenera. tion had taken place, and histologically the nerve was shown to possess many fine myelinated fibres. Ten days later the animal was killed, and the portion of the nerve below the resection was ex. amined; no myelinated fibres were found, but a number showing Wallerian degeneration. If the sheath cells had been mainly instrumental in the formation of the new regenerated fibres, resection of the piece of nerve should have had no influence upon the nerve which had developed from the sheath cells.

The changes which occur in the central end of the cut nerve were very incompletely known before Cajal intro. duced his silver method, and the histological observations of Peroncito, Cajal, and Marinesco by this method have thrown a new light upon the process of regenera. of these end in a terminal bulk. C, The axis cylinder
swollen in a still more marked manner, and consisting
above tion. tresses of neuro-fibrils. These reunite into cords
below, which surround more or less the débris of a
degenerated axis cylinder. (After Marinesco). of these end in a terminal bulk. C, The axis cylinder
swollen in a still more marked manner, and consisting
above tion. tresses of neuro-fibrils. These reunite into cords
below, which surround more or less the débris of a
degenerated axis cylinder. (After Marinesco). of these end in a terminal bulk. C, The axis cylinder
swollen in a still more marked manner, and consisting
above tion. tresses of neuro-fibrils. These reunite into cords
below, which surround more or less the débris of a
degenerated axis cylinder. (After Marinesco). of these end in a terminal bulk. C, The axis cylinder
swollen in a still more marked manner, and consisting
above tion. tresses of neuro-fibrils. These runite into cords
below, which surround more or less the debbris of a
degenerated axis cylinder. (After Marinesco). collateral ramifications of the axon, terminating after a short course, in very delicate filaments. After
eighteen hours he has observed in the central end most of the anatomical conditions indicative of regeneration, which, previous to his researches, had been looked upon as late productions of the axis cylinder-namely, the plaquette, the ring, the button, and the helicoidal formation. [Plate II-1.] These 
observations of Peroncito show that active nutritive changes commence almost directly after the injury before the sheath cells divide. Marinesco has confirmed the observations of Peroncito, and has found that within twentyfour hours of section of the sciatic nerve very important and interesting phenomena of regeneration occur. These phenomena are the results of an increased nutritive activity associated with a swelling and hypertrophy of the large axis cylinders, whereby the constituent nerve fibrils which make up the axons become evident. The network or skein of fibrils are clearly seen, owing to a great increase of the interfibrillary substance, and a longitudinal dissociation of the bundle of fibrils takes place. These skeins of fibrils may run side by side or intercross one another. The various appearances of the fibrils resulting from this longitudinal dissociation are represented in Fig. 4, and are very different from one another. Between the tangled skeins of dissociated fibrils there may be off. shoots of more delicate fibrils forming plexuses. Some of these delicate fibrils, as Fig. 5 shows, terminate in a little olive or cone of growth. This process of longitudinal phase of very active growth, which assures the neurotization of the peripheral end of the divided nerve. After the stage of active ramification or dendro-amoeboidism num. bers of terminal clubs of the young fibres are seen. These traverse paths rendered free to their passage between the sheath cells. Marinesco thinks that these: terminal clubs only indicate a delay or retardation of chimiotropism of the sheath cells. The shape of these terminal bulbs, which are so striking a feature of the regenerating nerve fibrils, is variable; in structure they consist of a network or twisted skein of fibrils in the form of an olive or bulb and an interfibrillary amorphous substance (Plate II-2). It is difficult to decide whether these bulbous terminals represent cones of growth or a twisting up of a fibril on account of an obstacle to the growth or nutrition of the nerve fibril.

If sections be made of the junction of the central and peripheral ends at successive periods of time, three stages can be seen : (1) The sprouting of large numbers of new fibres from the central cut axon; (2) the penetration of the bridge of young vascular connective tissue joining the cut

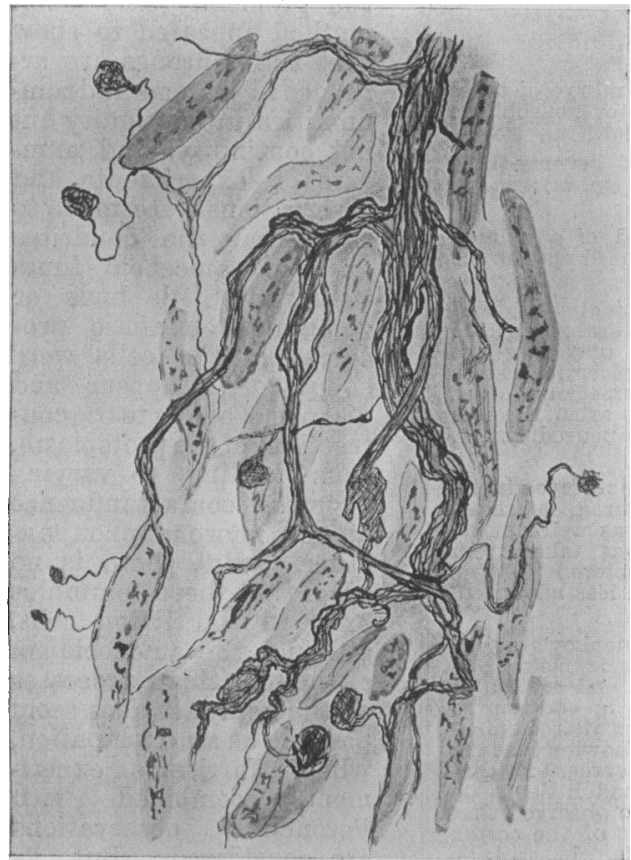

Fig. 5.- Hypertrophied fibres with very obvious fibrilis presenting an abundant lateral and terminal division. Some of the collateral and terminal ramifications are seen ending in a small or large bulb; others have a free extremity. The proliferated
sheath cells are very obvious. (After Marinesco).

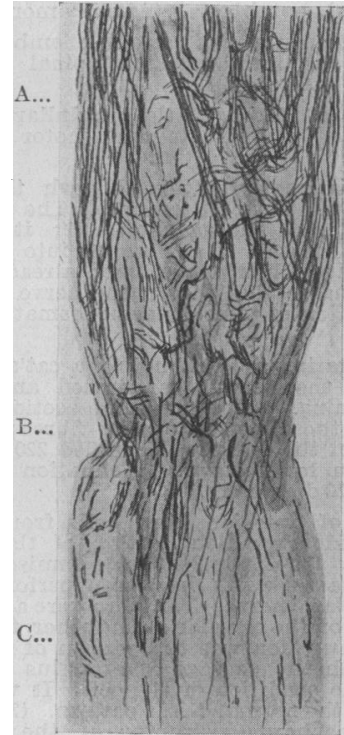

Fig. 6. - Longitudinal section of the sciatic nerv days after dog eigh Central ter Creripher , Cicatrix. Marinesco.)

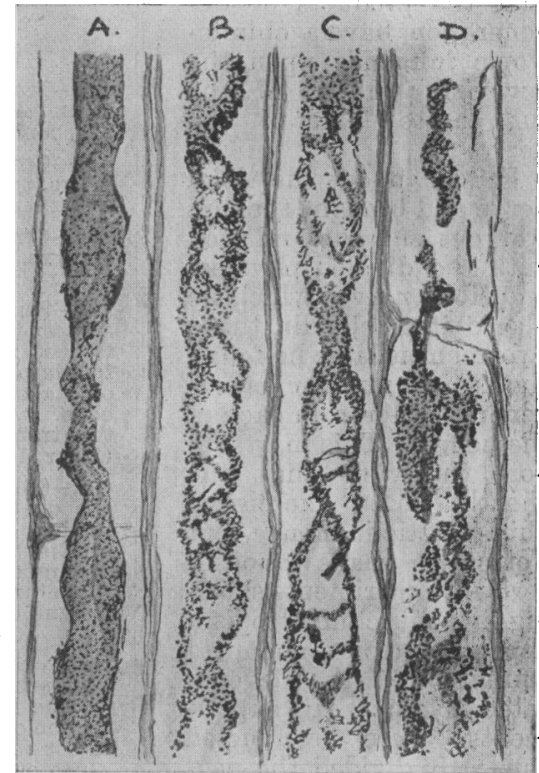

Fig. 7.-Represents four fibres showing different degrees of exolysis. A, The axis cylinder no longer shows any neuro-fibrils but consists of abundant fine granules disseminated in the interfibrillary substance. $B$, Formation of cavities and vacuoles in the interior of the axis cylinder, in consecuence of resorption of the granules. , The same condion brearing int , Marinesco.) fibrillary dissociation of the axon leads to the formation of a number of embryonic fibres, from which develop a number of young axis cylinders. These young fibres can be followed through the central cut end to the cicatrix. Some are seen to terminate in a button, olive, or club-shaped extremity, forming a cone of growth which penetrates between the more or less longitudinallyarranged sheath cells. [Plate II-7.] At the termination of the cut ends there is a cellular exudation and newformed blood vessels; this undergoes organization, and at the end of six or seven days forms a bridge which unites the two cut ends for the passage of the young regenerating fibres. But in proportion as the axon fibres penetrate the cicatrix they diminish in numbers and their branches are less numerous. The new fibres may be seen to diverge, intercross, and form a felt work, as seen in Fig. 6. A certain number of them, however, can be seen taking a straight course and descending vertically in the peripheral stump. Cajal considers that the terminal bulbs correspond to the cone of growth of the developing axon in the embryo or pseudopodia in the advancing axon of the neuron observed by Harrison in his experiments. Pro. bably Cajal is correct in maintaining that the terminals of the new-formed young fibres correspond to an amoeboid ends by the young nerve fibres; and (3) the penetration and growth downwards of these young fibres between the proliferated sheath cells of the peripheral portion [vide Plate II-7]. There can be no doubt, then, that the new nerve fibres depend upon an outgrowth from the central cut end of the neuraxon.

What part, then, we may ask, do the sheath cells play in regeneration?

To answer this question it is well to consider some of the appearances presented by the peripheral fibres which are undergoing Wallerian degeneration when stained by the Cajal silver method. The lesions are the same in all animals, but the moment of their appearance depends upon the species, age of the animal, and severity of the injury which has caused the solution of continuity of the nerve. The changes appear first at the upper end and are propagated peripheral-wards through the whole extent of the nerve below the lesion. The degeneration does not affect all the fibres equally. The first change is a swelling of the axis cylinder whereby the fibrillary network is displayed. The neuro-fibrils are visible and appear thickened in their course. But very soon the axon appears only as a dark stained finely granular cord (Fig. 7, A). In place of neuro-fibrils there is a dark mass of fine granules. 
Marinesco terms this condition "axolysis." He believes that the fragmentation of the myelin sheath and axis cylinder constitate connected phenomena dependent upon the same cause, namely, the formation of a digestive ferment on the inner surface of the sheath of Schwann. He moreover considers the ferments formed are analogous to the proteolytic and lipolytic ferments of the pancreatic juice, for Bokay has found that the pancreatic juice splits locithin up into cholin glycero-phosphoric acid and fatty acid. It is the oleic acid which stains black with the Marchi reaction. Resorption occurs in this softened and swollen axon, catsing vacuolation. The vacuolation becomes more marked as the process of resorption continues, and this results in fragmentation of the axon, and finally the fragmented axon is completely destroyed and absorbed (Fig. 7, B, C, D). The sheath cells undergo rapid proliferation and exercise a phagocytic action upon the products of degeneration, while others arrange themselves in a longitudinal direction to receive and attract the rapidly growing young fibres which have come from the central cut end. The experiments of Forssman appear to show that the products of degeneration have a chimiotropic influence upon the developing fibrils of the cut central end of the nerve.

Forssman cut the tibial nerve and brought the cen. tral cut end into relation with the divided peroneal and tibial nerves which he placed in a celloidin tube two months later he found the same number of regenerated fibres in each of the nerves. This may support the view that the sheath fibres exercise a chimiotactic influence, but Forssman made another series of experiments showing that this chimiotropism depends upon chemical attraction of the degenerated myelin. His experi. ments were conducted thus : He divided the cen. tral end of a nerve and placed each half into two separate celloidin tubes; one was filled with emulsion of liver and the other with brain emulsion; the fibres all grew in a direction towards the tube con. taining the brain emulsion. It may be concluded from this experiment that the degenerated myelin of the peripheral portion of the nervo attracts the young fibres and the sheath cells ensheath them.

Forssman also showed that the fibres of the central end do not take the line of least resistance, but the direction to which chimiotropism attracts them. Cajal, however, asserts that it is the attraction of the protoplasmic strands formed $b \nabla$ the sheath cells which are arranged in dense fusiform bundles, and $\mathrm{Cajal}$ and Marinesco believe that these neurilemmal cells secrete a chimiobropic substance capable of exciting a moeboid movement in the pseudopodia of the young regenerating axons, and having attracted, direct and nourish them. Marinesco claims to have proved this by the following experiments. He took a piece of nerve in which the shoath cells are dead; it was obtained either from a dead animal or by resection of a piece of nerve from a living animal which was allowed to remain a sufficient time in serum for death of the sheath cells to have taken place. This was connected to the central cut end of the sciatic nerve of an animal. To the central end of the other divided aciatic nerve he connected a piece of nerve kept alive in Locke's oxygenated serum. In the former case, when the sheath cells are dead there is no chimiotropic influence upon the fibres of the central cut end, whereas in the latter, if the resected nerve is from the same species, the fibres of the central end grow in. As the cell processes grow down into the new sheath an interaction takes place between the new axis cylinder and its sheath, leading to the formation of 'intervening myelin. Moreover, Halliburton and I found, in regenerating nerves, a much larger number of myelinated fibres and the myelin sheath of the fibres thicker near the point of section than in a remote portion of the nerve [vide Plate II-5]. This was an indirect support to the outgrowth theory, and has also been observed by Langley and Anderson.

It may be assumed, therefore, from what I have said, that the trophic and genetic independence of the neurone has been established. A question still remains, and that is, How are these nervous units connected with one another-if they are independent, how are they functionally correlated? This has, from the foundation of the neurone concept, been a point in dispute. Although many valuable researches have been published, still we are far from understanding the problem. The Golgi method appeared to show that the neurones are ar ranged in systems and com. munities in contiguity but not continuity, and num. bers of experiments and observations were made to show that the dendrites exercised amoeboid functions, and little buds or gemmules on these processes of the cells were supposed to appear and disappear owing to the contractility of the protoplasm, thus leading to varying degrees of contact influence of one neurone upon an other. But there is no proof that these gemmules exist in the living cells, although the amoeboidism of the branching processes of the neurones does secm possible as an explanation, when Harrison's experiments combined with Peroncito's observations are considered. But, as Verworn justly remarks, we must be careful not to generalize upon insuffi. cient data, for the physiological connexions in the nervous system of the lowest types of animals as compared with the higher vertebrates are different; take, for example, the simple reflex processes in the lower invertebrates and the complicated processes of association in the human brain. In the invertebrates there can be no question that Apathy and Bethe are right in asserting that there is a fibrillary continuum through several ganglion cells.

But does a continuity exist in the vertebrates? In my Croonian lectures on the Degeneration of the Neurone, I referred in the following words to some important researches of Held which had been put forward to disprove the neurone theory. "In my opinion, however, one can still accept the neurone theory and admit the truth of Held's observations-namely, that the terminal arborization of the axis cylinder process of one neurone forms protoplasmic concrescences by fusion with the cell body and dendrons of another. This, of course, implies continuity of the protoplasm of one neurone with another, but trophically and genetically the two are independent, and it is merely a question of degree of contact of the protoplasm of one with the other. Held agrees with other investigators that in embryonic tissues, and even 


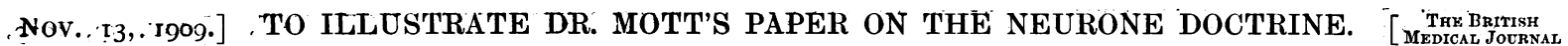

PLATE I.

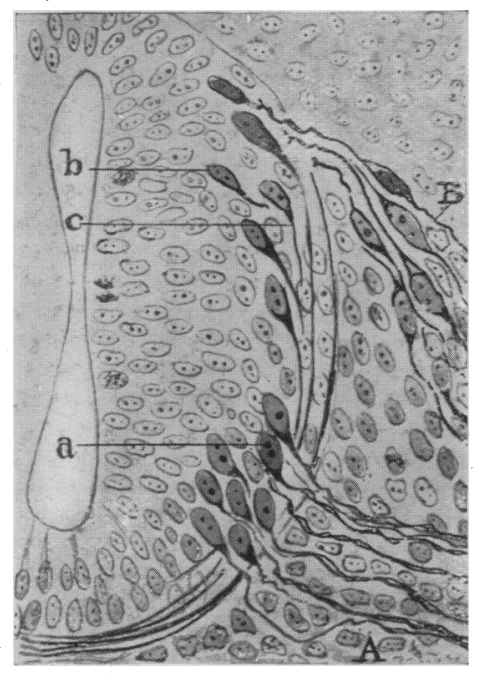

1.

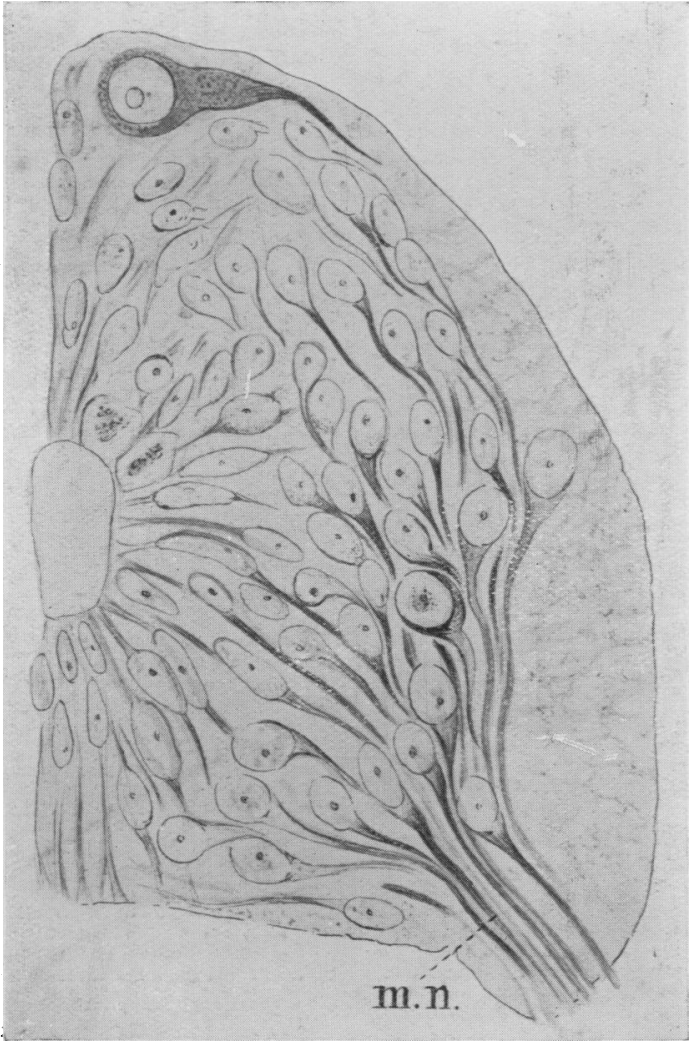

3.

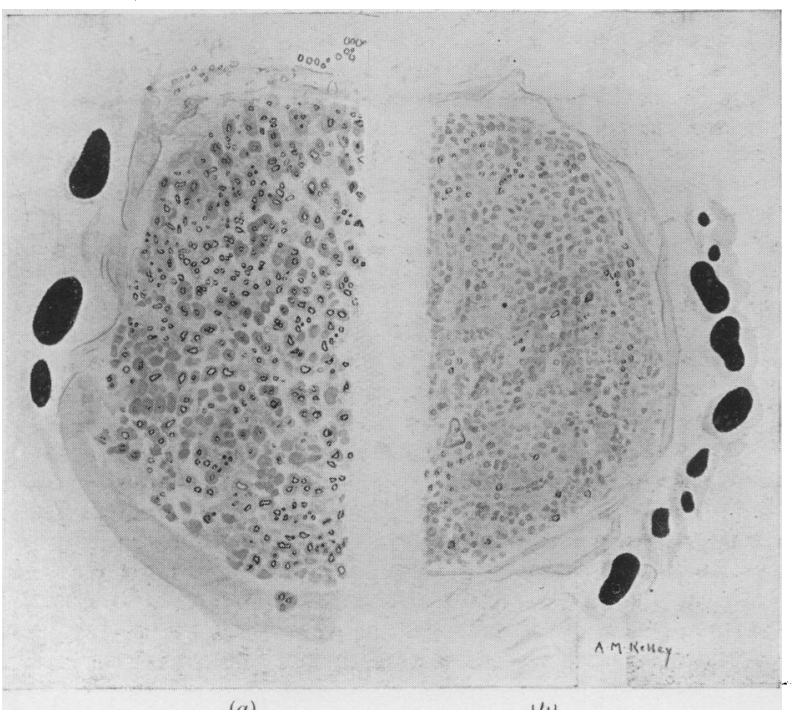

5.

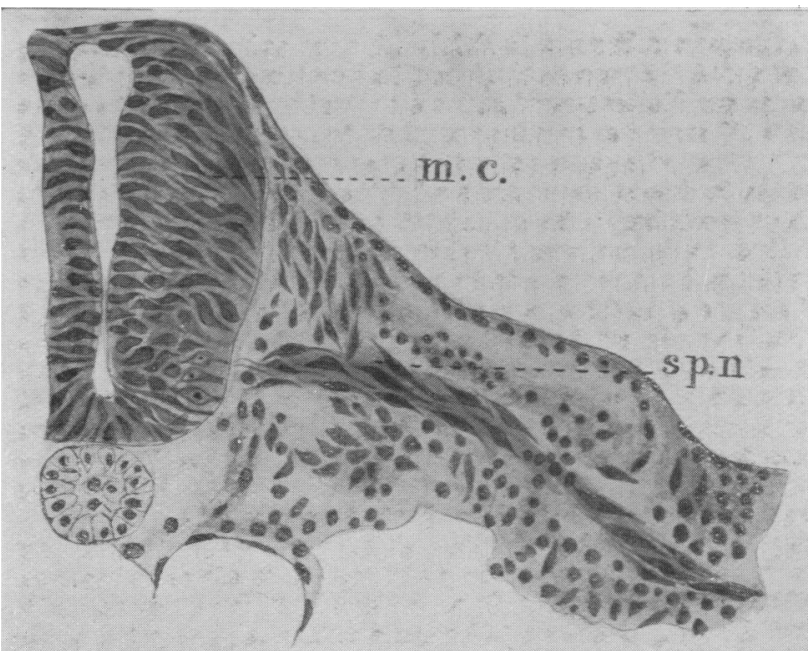

2.

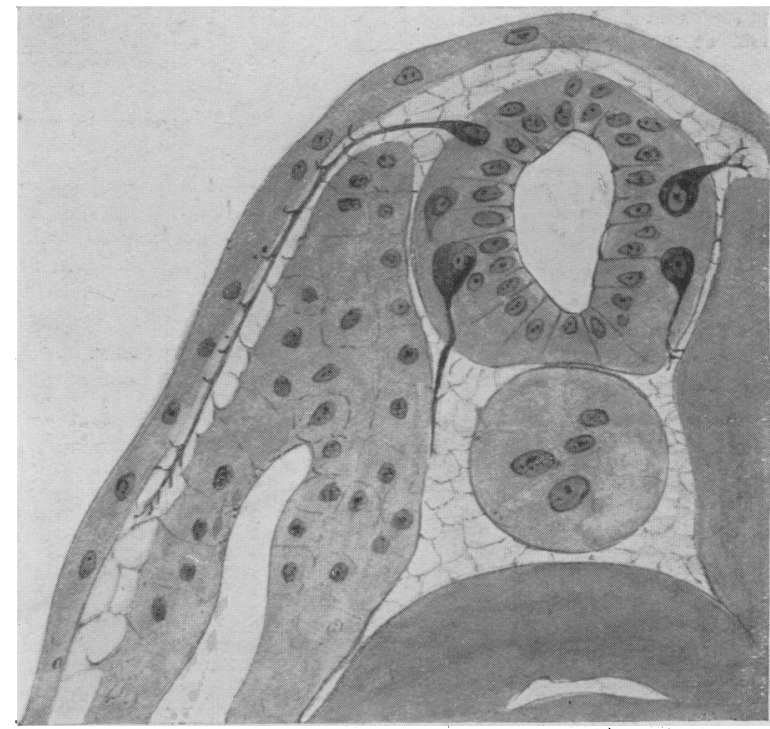

ד.

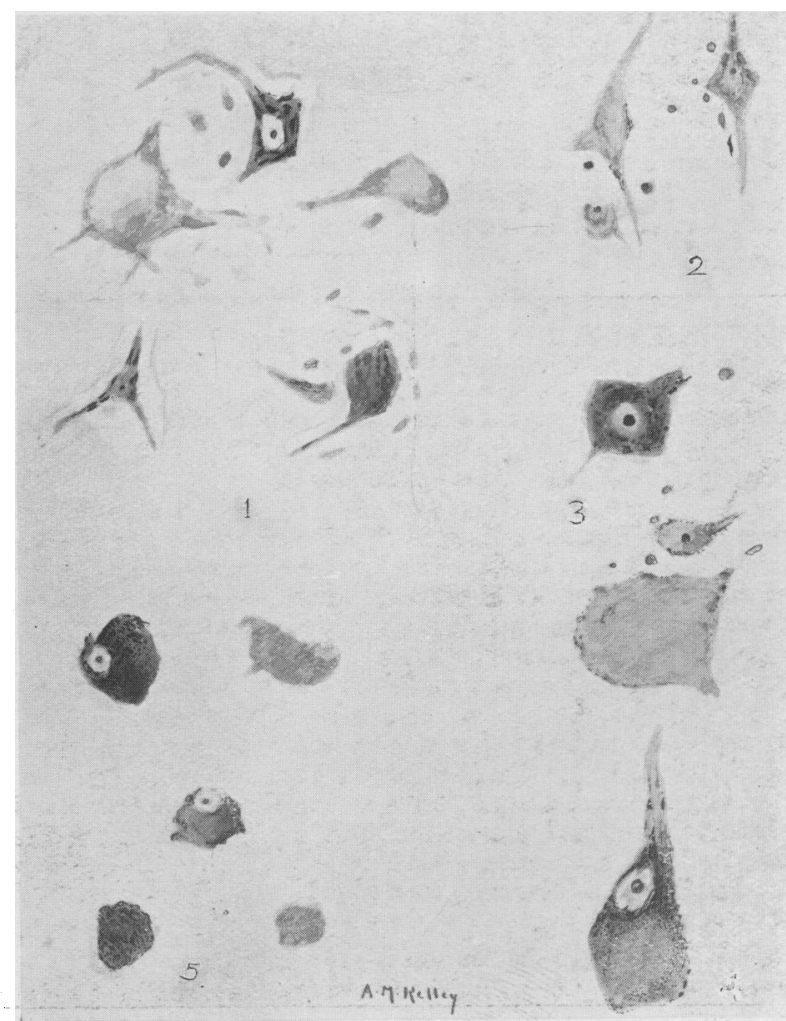

6. 
$\underset{\text { MEDICAL JOORNAL }}{\text { The RRTSR }}$ TO ILLUSTRATE DR. MOTT'S PAPER ON THE NEURONE DOCTRINE. [Nov. 13, I9Og. PLATE II.

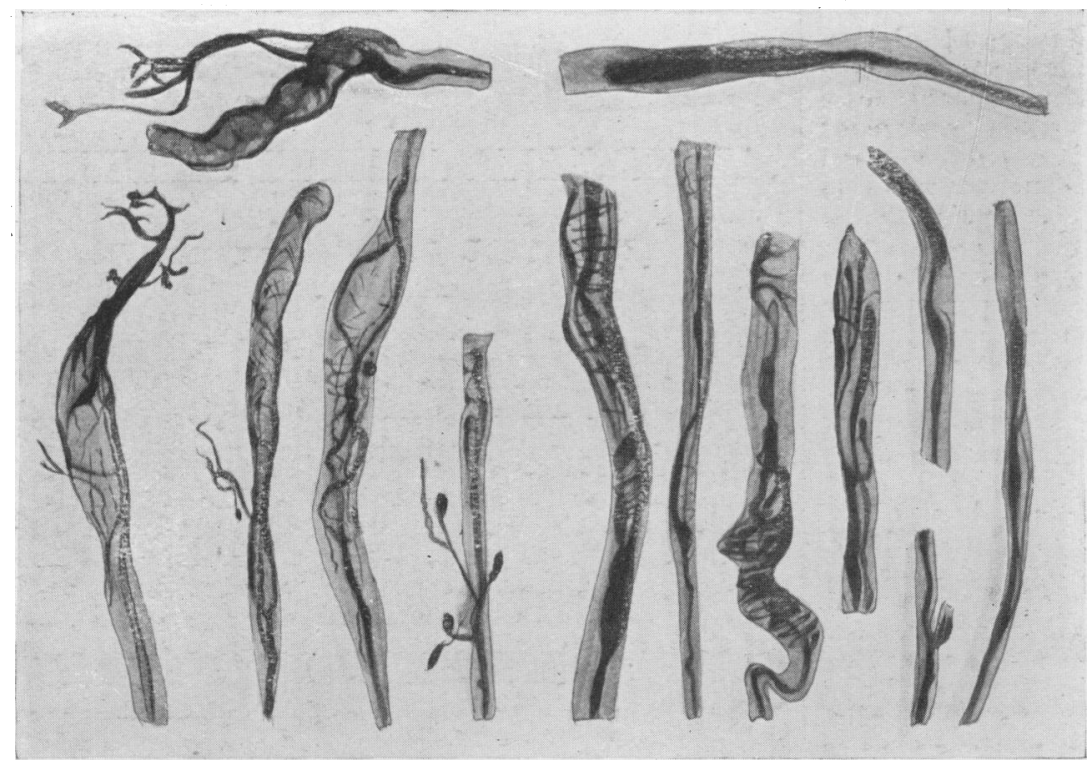

1.
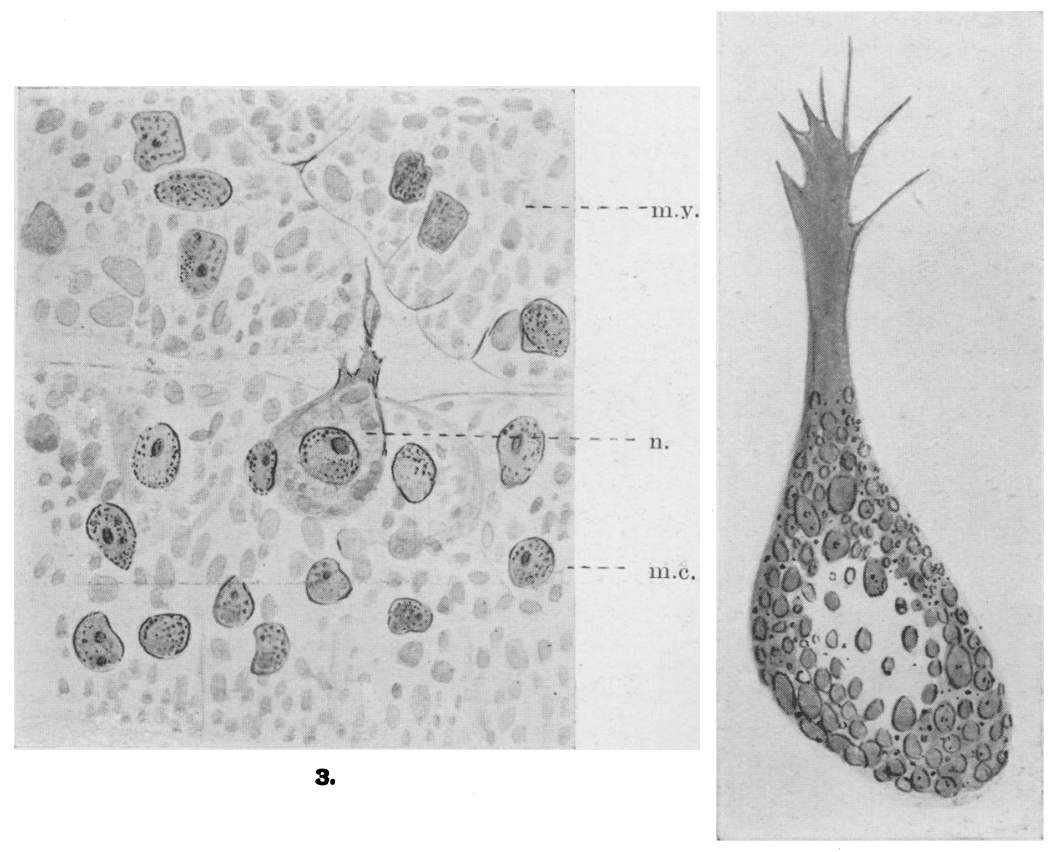

4.

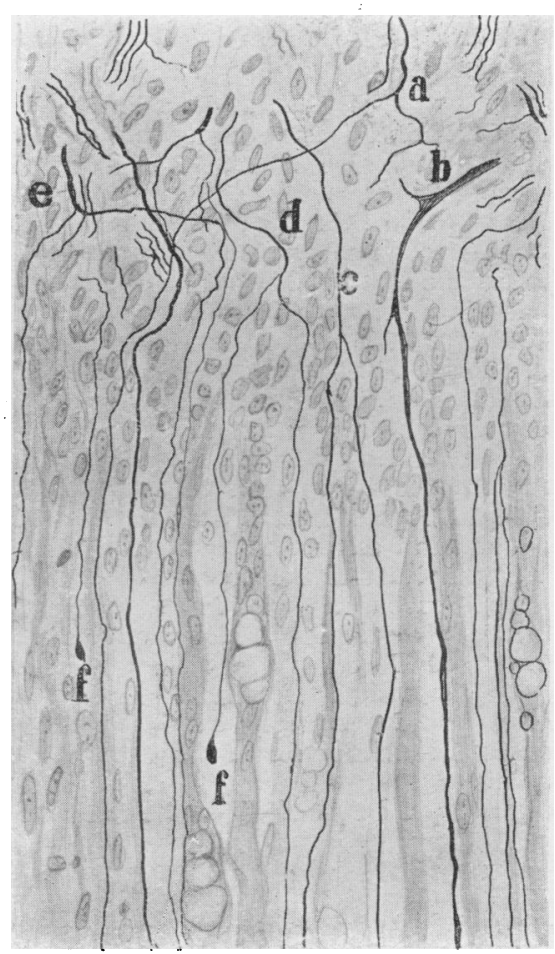

7.

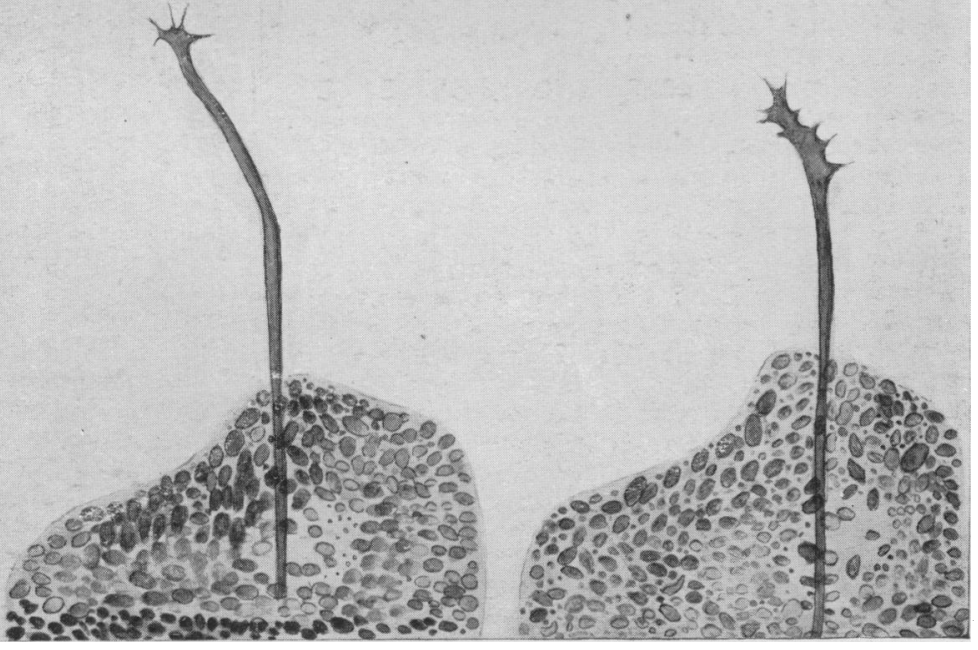

5.

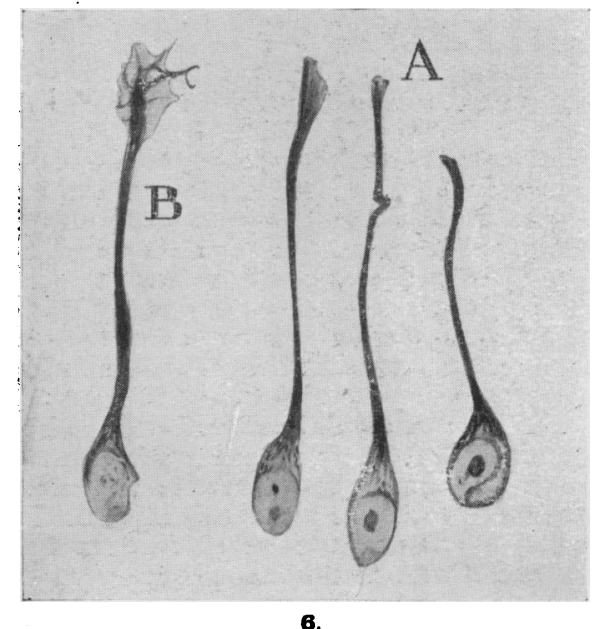


in early life, the neurones are entirely independent of one another.; This independence he can determine by a line of demarcation at the points of contact due to a difference in refraction. This refractile limiting line is; however, not demonstrable in the adult, and he comes to the conclusion that during the process of growth the protoplasm of related neurones fuses." . Verworn states that the pictures which Held publishes are not clear enough to satisfy him. On the other hand, the possibility is : undeniable that where the axon of one neurone is in contact with the dendrites of another there is a "receptive substance," which Sherrington hais termed the synapse; this substance may possess certain physiological properties which have a similarity with those of the end organ in striped muscle-for example, easy fatiguability, great summation, capacity for excitations, and specific reactions for certain poisons, etc. "But it remains undecided whether the acceptance of such a synapse having the above related physiological properties is neces. sary for the explanation of the physiological processes. 'In any case great difficulties exist both for the acceptance of the synapse as for the acceptance of a continuous path of conduction. It is a fact that conduction of the stimulus through the reflex arcs only occurs in the physiological and not in the opposite direction. Yet it can be demonstrated that the nerve possesses conductibility in both directions; therefore the necessary conditions for this difference of con. dactibility must be in the centre. Where the conditions are situated and how they are affected, the future must decide." It is admitted that the lower we descend in the zoological scale the more obvious is the fibril. lary continuum, and the simpler and less varied are the motor adaptations to environment. We may as. sume, therefore, that in the upward development of the animal series with the com. plexity and refinement of motor adaptation there coexists a neuronic independence. We may ask the question, What would be the advantage in the evolution of the, nervous system of neuronic independ. ence? In the attempt to answer such a question it is

desirable to look at it from a broad biological standpoint. What are the properties of nerve tissue. and how does it differ from other cell protoplasm? We may say it is irritable and conductile, but we know that the protoplasm of the carnivorous plants-ihe sundews and Venus flytrapis irritable, conductile, contractile, and secretory, and these plants are capable of exhibiting reflex action without a nervous system when the appropriate stimulus is applied. This reflex action, however, differs from that of the plantlike animals with their diffuse network of neuro-muscular cells in speed of reaction.

Consider, moreover, the ad rantage of speed of voluntary action initiated in the brain by the impulse having to pass through the conductile fibrils of only two nervous cells in the production of motor reactions of the arm, leg, face, and tongue. But if there existed a fibrillary continuum from the corebral nearone through the anterior spinal neurone, how could the anterior motor spinal neurones form the "final common path" for a multitude of different muscular activities ?

The idea that the neuraxon of a Betz psycho-motor cell is connected by its conductile fibrils with one anterior spinal motor neurone is a textbook mytb, which instead of making the nature of volintary movements to the thoughtful student clear, only makes him ask the question, Are the number of fibres in the pyramids of the medulla equal to the sum of all the fibres in the anterior roots? Clearly the fibrils, then, of the Betz cells must be connected with a number of spinal motor neurones forming the final common path for a multitude of different voluntary muscular activities. Moreover, we know that there is not a direct connexion between the upper cerebral neurones and the lower spinal motor neurones, for intercalary neurones with axons which do not leave the grey matter intervene and the terminal arborization of sensory afferent neurones, cerebra], mesencephalic, and bulbar efferent neurones, combine with spinal association neurones through the intercalary neurones in augmenting and inhibiting the outflow of energy of the spinal motor neurones, whereby the most varied, refined, and complex muscular reactions in adaptation to environment are effected. The nervous energy is expended in the grey matter of the brain and spinal cord.

There are many sther interesting points concerning the neurone which I might, had time permitted, have spoken about-for example, the significance of the nodes of Ranvier and the perifibrillary protoplasm; the theories in respect to the functions of the interfibrillary chromophilous substance of the ganglion cell and the dendrons. Is this chromophilous substance the source of nerve energy, and if so, is it used at the seat of its formation, the nerve cell, or is this substance, which in the dead cell corresponds to the Nissl granules, a store of energy.producing substance in the latent state analogous to the proferment of secretory glands-a substance which is transformed into the active energy.producing substance at the terminal arborizations of the neurone? I must, however, rest content if the facts and arguments .which I have related havesatisfied you that the neurone doctrine, pronounced dead only a few years ago, now rests on a surer basis than ever, this satisfactory result being due especially to the introduction of new methods of investigation by Ramon y Cajal and Harrison.

\section{Bibliography.}

1 Waller: Minute structure of the Papillae and Nerves of the 'Yongue of the Frog and Toad Phil. Trans., 1849, Experiment on the Glosso-pherynges an Phil Trans.

il. Trans., 1850.

2 Verworn: Bemerkungen zum heutigen Stand der Neuronlehre, 3 Mott. The rroonis L The Degeneration of the Neurone The Degeneration of the Neurone; BRITISH MEDICAL JoURNAL, 1900. ${ }^{4}$ Schultze, Oskar: Beiträge zur Histogenese des Nervenssystem Ueber die multizellulare Enstehung der

faser, Arch. f. mikr. Anat., 1905, Bd. 66 .

Ramon y Cajal: Trabajos de Laboratorio a Investigaciones Biologicos de la Universidad de Madrid. Tome iv. Madrid. 1906; Génesis 1890; Bd. 30, 1907; and Bd. 32, 1908.

6 Harrison, Ross Granville : Embryonic Transplantation and Develop ment of the Nervous System, Anatomical Record, vol. ii. No. 9, December, 1908; Experiments on Transplanting Limbs, Journal of Experimental Znology, vol iv. No 2; Regeneration of Peripheral Nerves, Anatomical Record (No. 8) of the American Journal of Anatomy, vol. vii, No. 4; Observations on the Living Developing Nerve Fibre, American Journal of Anatomy, 1907, vol. vii.

7 Held : Verhandlungon der anatomischen Gesellschaft, Rostock, 1906́: Anatomischer Anzeiger, Bd. 30, 1907.

${ }_{8}$ Perroncito: Zeigler's, Beiträge zur pathologischen Anatomie und zur allgemeinen Pathologie, Bd. 42, 1907; Sur la question de la régénération autogène des fibres nerveuses, A rchiv. Ilal. de Biol. ol. xliv, 1905. No. 3

10 Bethe: Allgemeine Anatomie und Physiologie des Nervenssystems. Leipzig, 1903.

der Saitget hiere. Entwickelungsmoch unit,

(1) générescence autogellulev neurcl. No. 23 , 1905 , Racherches sur la régénérescence des nerfs périph.. Rev. neurol, No, 5,1906

I3 Marinesco et Goldstein: Recherches sur la transplantation des ganglions nervenx. Comptes rendus de l'Acadèmie des Sciences, Fehruary 18th, 1907.

Fis Marinesco et Miner: Nouvelles recherches sur in transplantation des ganglions nerveux. Comptes rendus de l'Acaldmic des Sciences. February 25th, 1907.

15 Nageotte: Greffe des ganglions rachidiens, Soc. de Biol., 19 janvier, 22 fév. et 9 mars, 1907.

16 Mott and Halliburton: Proceedings of the Royal Sociefy, B., vol. $1 \times x v i i i, 1906$, p. 259, in which is contained a number of references to the oriqinal work done on regeneration of nerves.

17 Forssman:'Zur Kenntniss des Neurotropismus. Ziegler's Beitrüge zur path. Anatom.'und zur' allgem. Path. Bd. 27, 1900. 